\title{
Challenges Of Inquiry Based Learning In Physical And Health Education
}

\author{
Betna Adiguna ${ }^{1}$, Panggung Sutapa ${ }^{2}$ \\ \{betnaadi@gmail.co ${ }^{1}$ \} \\ ${ }^{1,2}$ Universitas Negeri Yogyakarta, Yogyakarta Indonesia
}

\begin{abstract}
Inquiry based learning (IBL) is a learning process in which students engage in their learning, formulate questions, investigate extensively and then build new knowledge. The key role of physical education is to encourage the development of cognitive and physical competencies to provide individuals with confidence and motivation to continue physical activities outside of school and maintain a healthy lifestyle. The IBL approach makes physical education relevant, meaningful, challenging and allows students to collaborate on assignments given in a safe and positive context. This factor affects student motivation positively and can encourage students to continue physical activities outside of school. Systematic reviews to identify the difficulties and challenges faced by physical education and health teachers using IBL as a learning method. The article search on Scopus by using keyword inquiry based learning and physical education. Based on our literature review, identified six challenges that affect the learning outcomes using IBL.
\end{abstract}

Keywords: Inquiry based learning, Physical and health education

\section{Introduction}

Inquiry based learning (IBL) is a learning process in which students engage in their learning, formulate questions, investigate extensively and then build new understanding, meaning, and knowledge. Knowledge is used to answer questions, to develop solutions or to support a view. This knowledge is presented to others and can produce an action [1]. Inquiry provide valuable opportunities for students to improve their ability to understand scientific content and scientific practice [2]. This learning method involves several phases: orientation, conceptualization, investigation, conclusion and discussion [3].

The orientation phase is focused on generating student interest and curiosity about the problems. Output from this phase is a problem statement. Conceptualization is the process of understanding the problem concept. At the end of the conceptualization stage students make open questions that relate to the problem and formulate hypothesis. Students then look for answers to the questions and hypotheses arranged at the investigation stage. Students collecting data by exploring and experimenting. The data collected is then interpreted into a new knowledge that will be used to answer the hypotheses that have been compiled at the conclusion stage. students present the results of data collection during the investigation phase at the discussion stage to get comments and input. when discussing, students learn to listen others opinions and maintain their views. The learning process ends with a reflection of the learning [3]. 
Ecohydrological system learning using IBL in Texas students produce a better conceptual understanding than conventional learning methods [4]. Application IBL in science class resulted in a higher academic score compared to traditional learning methods [5]. IBL makes students more engaged in the learning process and understand the learning material better [6]. The key role of physical education is to encourage the development of cognitive and physical competencies to provide individuals with confidence and motivation to continue physical activities outside of school and maintain a healthy lifestyle. The IBL approach makes physical education relevant, meaningful, challenging and allows students to collaborate on assignments given in a safe and positive context. This factor affects student motivation positively and encourage students to continue physical activities outside of school [7].

The application of IBL in the learning process faces several challenges. In science class, there are five challenges faced by the IBL method. The first challenge is motivation, the IBL method requires higher motivation from students to contribute compared to other traditional learning methods. The second challenge is students must understand what is needed in the investigation process. Students must understand the purpose of learning and can interpret the obtained results. Scientific investigation require a higher level of accuracy and attention than doing daily activities. The third challenge is the formulation of research questions, arranging research plans, collection, analysis, and interpretation of data all require knowledge of science content The fourth challenge is to achieve the final goal requiring the regulation and management of complex activities. Scientific investigation requires planning, coordinating activities, managing resources and work products that are not needed in traditional learning methods. The fifth challenge is the implementation of IBL must be in accordance with the resources and schedules available [2]. As in science class, the application of IBL in the process of learning physical and health education also found several challenges. This article aims to identify the challenges faced in using the IBL method in the learning process of physical and health education.

\section{Method}

A systematic review was conducted to identify the challenges faced in applying the IBL method in PJOK learning. The data base used is SCOPUS by using the search term: Inquiry based learning and "physical education". Reviewers assess the title and abstract of all identified studies. All studies that potentially meet the requirements are reviewed in the article. Articles included in the study must meet the following requirements: 1) research conducted on school-age children 2) learning methods carried out in research is inquiry based learning 3) lessons studied are physical education or health education 4) research articles discuss the challenges of implementing IBL. Figure 1 shows a process diagram for selecting research articles used in a systematic review. The reviewer also conducted interviews with two PJOK teachers to find out the challenges faced in applying the IBL method. 


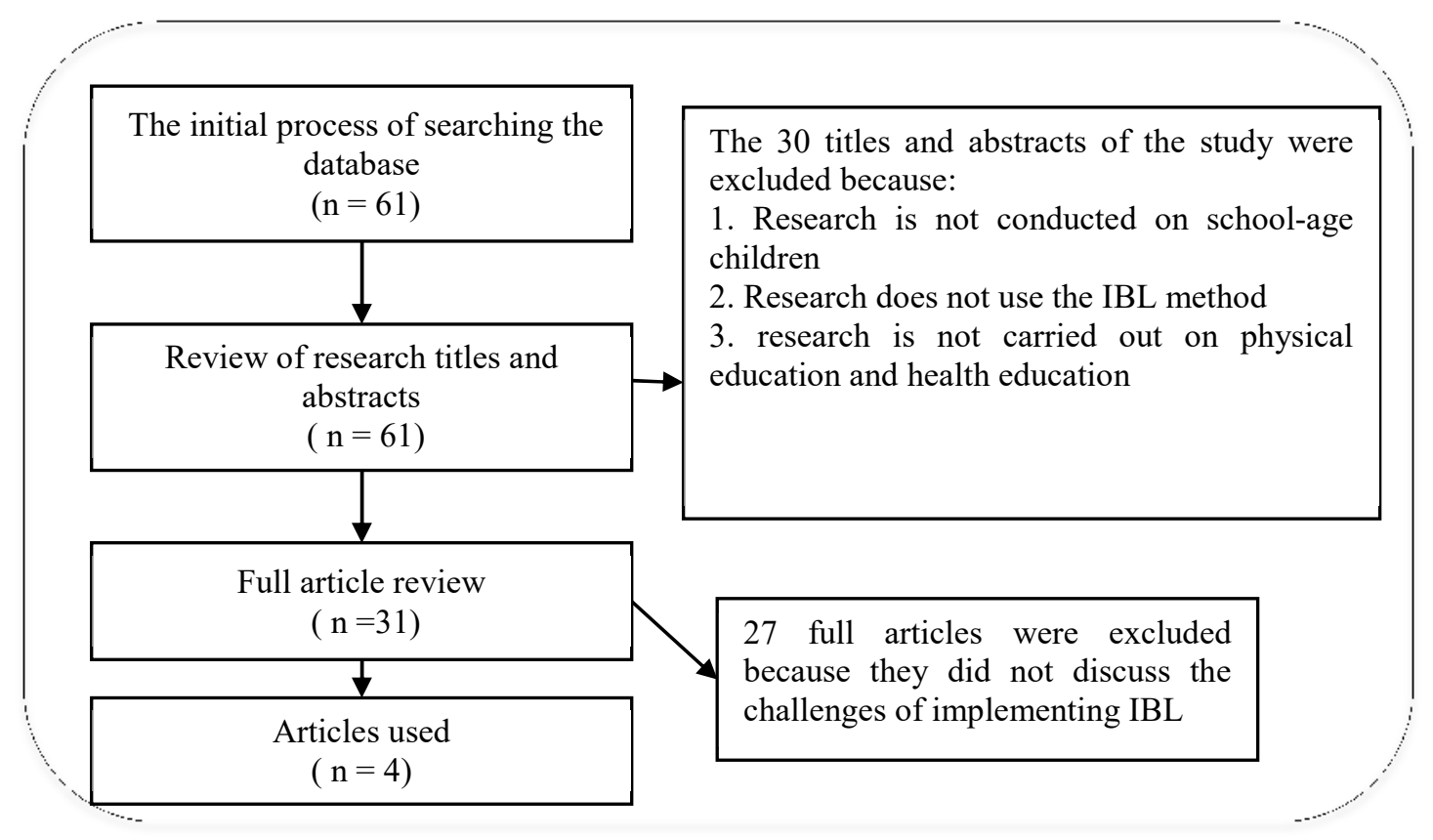

Fig. 1. systematic review was conducted to identify the challenges faced in applying the IBL method in PJOK learning

\section{Results and Discussion}

The initial search on the database found 61 articles that matched the search keywords. A review of the title and abstract of the article was only 31 articles carried out on school children, using IBL as a learning method in physical education and health. A full article review of 31 articles found 4 articles (table 1) which discussed the challenges of implementing IBL in learning physical and health education.

The reviewer interviewed two teachers to find out the application of IBL in physical and health education. the interview results showed that they did not know and understand the IBL method, so they never applied it in learning activities.

The IBL method can provide constructive understanding, because this method encourages students to think about problem solving [9]. In physical education students can be more involved in the activity of increasing knowledge (cognitive) and physical (psychomotor) activities [8]. The involvement of students in more depth is expected to be able to make students' motivation higher to do physical activities outside of school (Affective) [7]. The application of IBL in the learning process has several challenges that hinder the achievement of learning goals.

The first challenge faced is the motivation of students to get involved in the learning process [8]. IBL requires more motivation than traditional learning, because this method requires students to hypothesize and find answers to these hypotheses. The search process requires more time, so high motivation is needed to get good results [2].

The second challenge is teacher motivation. The teacher must facilitate and guide students for example by providing relevant literature information and references, or demonstrating equipment that can help students conduct further investigations [10]. This role requires a 
positive attitude, preparation and practice before this method can be applied [11]. Without high motivation, teacher will find it difficult to prepare for learning and practice the IBL method so that learning outcomes are not optimal.

The third challenge is student knowledge about IBL learning. The IBL method requires students to understand the instructions given by the teacher clearly. students must understand the instructions clearly so the learning process runs smoothly. if students do not understand the instructions then they will spend more time asking what they should do than to investigate the problem [8].

The fourth challenge is teacher knowledge about IBL. In IBL the teacher acts as a facilitator and mentor so that a teacher must understand how IBL must be implemented. The teacher must also be able to provide direction and motivation to students to conduct scientific investigations that require more precision and attention than what they do everyday $[7,10]$.

The fifth challenge is student communication skills. One phase in the IBL learning process is discussion. During the discussion students present the results of their investigation and get feedback. After the question and answer process, students reflect on the learning process. Limitations in communication skills will prevent students from expressing their opinions, responding to feedback from friends and teachers and maintaining their opinions [7].

The sixth challenge is structural support. The success of the IBL learning method requires not only the participation of students and teachers, but also requires support from the environment. Support from the school and the surrounding environment will provide the resources and time needed by students in scientific investigations [11]

\section{References}

[1] Lawlor, D. (2016) Inquiry-Based Learning in Health and Physical Education A Resource Guide for Educators. Edited by S. Seslija. Ontario: Ophea.

[2] Edelson, D. C., Gordin, D. N. and Pea, R. D. (1999) 'Addressing the Challenges of Inquiry-Based Learning Through Technology and Curriculum Design', The Journal of The Learning Sciences, 8(3), pp. 391-450.

[3] Pedaste, M., Mäeots, M., Siiman, L. A., Jong, T. De, Zacharia, Z. C. and Tsourlidaki, E. (2015) 'Phases of inquiry-based learning: Definitions and the inquiry cycle', Educational Research Review. The Authors, 14, pp. 47-61.

[4] Miller, H. R., Neal, K. S. M. C. and Herbert, B. E. (2010) 'Inquiry in the Physical Geology Classroom: Supporting Students ' Conceptual Model Development', Journal of Geography in Higher Education, 34(4), pp. 595-615.

[5] Maxwell, D. O. and Lambeth, D. T. (2015) 'Effects of using inquiry-based learning on science achievement for fifth-grade students', Asia Pacific on Science Learning and Teaching, 16(1), pp. 1-31.

[6] Zafra-gómez, J. L., Román-martínez, I. and Elena, M. (2014) 'Assessment \& Evaluation in Higher Education Measuring the impact of inquiry-based learning on outcomes and student satisfaction', Assesment \& Evalution in Higher Education.

[7] Østergaard, L. D. (2016) 'Inquiry-based Learning Approach in Physical Education: Stimulating and Engaging Students in Physical and Cognitive Learning', Journal of Physical Education, Recreation \& Dance, 87(2), pp. 7-14.

[8] Oliver, K. L., Oesterreich, H. A., Aranda, R., Archeleta, J., Blazer, C. and Cruz, K. De (2015) 'Physical Education and Sport Pedagogy “ The sweetness of struggle ": innovation in physical education teacher education through student-centered inquiry as 
curriculum in a physical education methods course', Physical Education and Sport Pedagogy, 20(1), pp. 97-115.

[9] Light, R. and Wallian, N. (2008) 'A Constructivist-Informed Approach to Teaching Swimming', Quest, 60(3), pp. 387-404.

[10] Connor, J. O., Jeanes, R. and Alfrey, L. (2016) 'Authentic inquiry-based learning in health and physical education : a case study of " $\mathrm{r} /$ evolutionary " practice', Physical Education and Sport Pedagogy, 21(2), pp. 201-216.

[11] Alfrey, L., Connor, J. O. and Jeanes, R. (2016) 'Teachers as policy actors : co-creating and enacting critical inquiry in secondary health and physical education in secondary health and physical education', Physical Education and Sport Pedagogy 